\title{
Beyond Confusion and Controversy, Can We Evaluate the Real Efficacy and Safety of Cholesterol-Lowering with Statins?
}

\author{
Michel de Lorgeril, ${ }^{1}$ Mikael Rabaeus ${ }^{2}$ \\ ${ }^{1}$ TIMC-IMAG CNRS UMR 5525, Laboratoire Cour et Nutrition, Université Joseph Fourier, Grenoble, \\ France; ${ }^{2}$ Clinique La Prairie, Clarens-Montreux, Switzerland.
}

\begin{abstract}
A strong controversy has emerged about the reality of safety and efficacy of statins as stated by company-sponsored reports. However, physicians need credible data to make medical decisions, in particular about the benefit/harm balance of any prescription. This study aimed to test the validity of data on the company-sponsored statin trial by comparing them over time and then comparing statins with each other. Around the years 2005/2006, new stricter Regulations were introduced in the conduct and publication of randomized controlled trials (RCTs). This would imply that RCTs were less reliable before 2006 than they were later on. To evaluate this, we first reviewed RCTs testing the efficacy of statins versus placebo in preventing cardiovascular complications and published after 2006. Our systematic review thereby identified four major RCTs, all testing rosuvastatin. They unambiguously showed that rosuvastatin is not effective in secondary prevention, while the results are highly debatable in primary prevention. Because of the striking clinical heterogeneity and the inconsistency of the published data in certain RCTs, meta-analysis was not feasible. We then examined the most recent RCTs comparing statins to each other: all showed that no statin is more effective than any other, including rosuvastatin. Furthermore, recent RCTs clearly indicate that intense cholesterol-lowering (including those with statins) does not protect high-risk patients any better than less-intense statin regimens. As for specific patient subgroups, statins appear ineffective in chronic heart failure and chronic kidney failure patients. We also conducted a MEDLINE search to identify all the RCTs testing a statin against a placebo in diabetic patients, and we found that once secondary analyses and subgroup analyses are excluded, statins do not appear to protect diabetics. As for the safety of statin treatment - a major issue for medical doctors - it is quite worrisome to realize that it took 30 years to bring to light the triggering effect of statins on new-onset diabetes, manifestly reflecting a high level of bias in reporting harmful outcomes in commercial trials, as has been admitted by the recent confession of prominent experts in statin treatment. In conclusion, this review strongly suggests that statins are not effective for cardiovascular prevention. The studies published before 2005/2006 were probably flawed, and this concerned in particular the safety issue. A complete reassessment is mandatory. Until then, physicians should be aware that the present claims about the efficacy and safety of statins are not evidence based.
\end{abstract}

Keywords: atorvastatin, cholesterol, chronic heart failure, chronic kidney failure, diabetes, myocardial infarction, pravastatin, rosuvastatin, simvastatin.

Received: 13 November 2015; Accepted after revision: 04 December 2015: Published: 12 January 2016.

Author for correspondence: Michel de Lorgeril, MD, TIMC-IMAG CNRS UMR 5525, Laboratoire Coeur et Nutrition, Université Joseph Fourier, Grenoble, France. Email: michel.delorgeril@ujf-grenoble.fr 
How to cite: de Lorgeril M, Rabaeus M. Beyond Confusion and Controversy, Can We Evaluate the Real Efficacy and Safety of Cholesterol-Lowering with Statins?. Journal of Controversies in Biomedical Research 2015; 1(1): 67-92. Doi: $\underline{\text { http://dx.doi.org/10.15586/jcbmr.2015.11 }}$

License: This open access article is licensed under Creative Commons Attribution 4.0 International (CC BY 4.0) http://creativecommons.org/licenses/by/4.0/

\section{Introduction}

There is a growing controversy affecting several drugs about their efficacy and safety, triggered by increasing signs of altered validity of numerous companysponsored trials. One example is the neuraminidase inhibitors for treating influenza $(1,2)$. The 5 -year battle needed to access the raw trial data led to a reversed picture of the drugs: benefits had been overestimated and harms under-reported in the company-sponsored trial reports (1, 2). Ultimately, the benefit/harm balance was not in favor of the drugs; this is a critical issue for physicians, in particular when they are in charge of fragile patients. One probable cause of the failure is that none of the trials was independent of the drug's manufacturers. Several experts conclude that the "Tamiflu story" may suggest that the entire ecosystem of drug evaluation and regulation could be flawed $(3,4)$.

These concerns were strongly reinforced by the recent "confession" by Dr. Rory Collins from Oxford University, a prominent expert investigator in the field of cholesterol epidemiology and cholesterol-lowering statins. He stated bluntly in the lay press that the evaluation of statins during the last two decades had not been done correctly (5). He admitted that "the nature and importance of their adverse effects have to be reassessed" (5). The Cochrane statins review group also admitted that they do not have proper data to evaluate statin safety (5). Curiously, this occurred just 1 year after a rather unusual dispute between several "experts" about adverse effects of statins (6-11).

Dr. Rory Collins being the head of several consortiums publishing huge metaanalyses - through the Clinical Trial Service Unit (CTSU) or The Cholesterol Treatment Trialists' (CTT) Collaboration, for instance - the whole story does raise major concern, for the simple reason that these meta-studies repeatedly claimed that statins are particularly safe (12-15); not forgetting that they served as a scientific basis for "lipid treatment guidelines" released by several national and international institutions $(16,17)$.

How then are physicians supposed to act when it is admitted today by the experts themselves that their evaluation works were not done correctly? Can we trust and follow the guidelines? In other words, what is the true benefit/harm balance of statins $(18,19)$ ?

The most adequate way to solve the issue would be to "open the doors" so that independent experts do have full access to the company-sponsored trial data sets - i.e., clinical raw data of each randomized patient in each trial - to examine their validity in terms of safety and efficacy. This has led to an intense debate about randomized controlled trial (RCT) transparency (20-30).

Prestigious scientists recently stated that modern medical scientific data are generally irreproducible (31-33), often wrong (34-38), going as far as claiming that "an estimated 85\% of research resources are wasted" (31, 32). As raw clinical data are still not available (lack of transparency), the US Food and Drug Administration (FDA) and the European Medicines Agency (EMA) cannot fully ensure that industry adequately conduct RCTs and fully report drug data regarding both efficacy and safety (20-41). One key measure to ensure RCT quality is the concealment of patient allocation and double-blinding. Not respecting one of these obligations may introduce unintentional bias in RCTs, in particular when clinical efficacy is based on "soft outcomes" - such as revascularization or hospitalization for chest pain, when 
evaluating cardiovascular drugs - or "composite outcomes" mainly including soft outcomes (42). A clear possibility of such an unintentional "unblinding bias" has been recently described (43). All these contribute to the emerging skepticism affecting the credibility of RCT data among both public and health professionals $(44,45)$.

There have been two periods in the modern history of RCTs: before and after the 2005/2006 New Clinical Trial Regulations. These were implemented by the Health Authorities in Europe and USA - following the Vioxx and Celebrex incidents among others - in order to bring more transparency into the pharmaceutical industry (46-50). The Legislator's intention was to force industrialists to make public all the RCTs they were setting up with the details of their main features, notably the dates of initiation and termination, including any discontinued RCT (46-50). Importantly, by implementing New Clinical Trial Regulations, the Health Authorities implicitly admitted that previous drug assessment procedures were not satisfactory. As these New Regulations were elaborated to provide more robust scientific data and more protection for the consumers, it could be hypothesized that RCTs published after 2005/2006 are more reliable than those published before 2005 .

Coming back to statins, in case of a significant discrepancy between the ancient (before 2005/2006) and the more recent (after 2005/2006) RCTs testing these drugs, we would conclude that only the results of the most recent RCTs should be retained. However, the absence of discrepancy between ancient and recent RCTs would be very reassuring and allow physicians to keep on prescribing statins as they did until now.

In order to provide more credible information to physicians and help them make the right decision regarding statin prescriptions, we have conducted a careful analysis of available company-sponsored statin RCTs published after 2005/2006. We then examined studies comparing statins to each other and whether intense statin regimens do protect high-risk patients better than less-intense statin regimens. Finally, we examined some safety issues including the very important statin-diabetes issue.

\section{Methods}

\section{Search strategy}

We identified RCTs published after 2005/2006 - and testing a statin against a placebo - via a MEDLINE search using the following key words "statins," "RCT," "placebo," "cardiovascular disease," "ischemic heart disease," "stroke," "myocardial infarction," and "mortality." The search was updated on March 2015 and retained only randomized double-blinded RCTs designed to examine the effects of a statin on cardiovascular outcomes during a period of at least 1 year. In addition, we examined the reference lists and related links of retrieved articles that met the inclusion criteria and expert review and published meta-analyses to detect all studies potentially eligible for inclusion. Crosssectional, cohort, case-control, and metaanalysis studies were not included. Studies comprising secondary and/or subgroup analyses were excluded because they were performed "a posteriori" after unblinding, a major cause of bias. We also performed a MEDLINE search to specifically identify double-blinded RCTs testing a statin in diabetic patients. Again studies comprising secondary and subgroup analyses were excluded. The selection was done by Michel de Lorgeril and verified by Mikael Rabaeus; and there was no discrepancy between them. The excluded references are included as supplementary file.

Because of major clinical heterogeneity of the RCTs published after 2005/2006, a metaanalysis was not feasible. Indeed, no metaanalysis of those RCTs has been published so far, the main reason simply being that it is not methodologically acceptable. We cannot put in the same database such very different cohorts of patients, namely patients in primary prevention (Justification for the Use of Statins in Prevention: an Intervention Trial Evaluating Rosuvastatin [JUPITER]), patients in secondary prevention with various degrees of cardiac dysfunction (Controlled Rosuvastatin Multinational Trial in Heart Failure [CORONA]), patients with heart failure (Gruppo Italiano per lo Studio della Sopravvivenza nell'Insufficienza cardiaca [HF] [GISSI-HF]), or patients with chronic renal failure (A Study to Evaluate the Use of Rosuvastatin in Subjects on Regular 
Hemodialysis: An Assessment of Survival and Cardiovascular Events [AURORA]).

In addition, as discussed further in the Results section, data of certain RCTs are not correctly provided. For instance, cardiovascular mortality in JUPITER is not reported in the first published article. Then, five different versions of cardiovascular mortality were reported. Which one should we consider? Moreover, regarding the overall mortality in JUPITER, the data were not validated by the statisticians of the FDA because the trial was prematurely stopped. We thus had to renounce to make any meta-analysis in the present study.

\section{Results}

\section{The statin efficacy data}

The only statin that has been tested (against placebo) after the implementation of the New Regulations is rosuvastatin that was tested in four RCTs (Figure 1 and Table 1):

- The JUPITER trial, wherein the patients were considered free from cardiovascular disease and carrying a rather moderate risk of cardiac death (51);

- The CORONA trial, wherein patients were all survivors of a prior acute myocardial infarction (AMI) - with various degrees of cardiac dysfunction and at high risk of AMI recurrence and cardiac death (52);

- The GISSI-HF trial, wherein all patients had cardiac dysfunction - $50 \%$ following a previous AMI and 50\% due to other heart disease - and a high risk of cardiac death (53);

- The AURORA trial, wherein patients presented with severe renal failure, with $50 \%$ having already suffered an AMI or other ischemic complications. Evidently, they had a major risk of recurrent AMI and cardiac death (54).

Thus, a large proportion of the patients recruited in these four rosuvastatin RCTs were in the context of secondary prevention, thereby testing what has become an apparently indisputable statement: "beyond any doubt, statins are effective in secondary prevention" (55-58). A corollary statement was also tested: "the higher the risk of AMI, the more the reduction of cholesterol levels by means of a statin will be beneficial" (55-58). The patients in AURORA - with the highest risk - should get the greatest benefit and those in JUPITER - with the lowest risk the least benefit. Let us start with the patients whose risk was the lowest.

\section{The JUPITER trial}

The JUPITER trial was a primary prevention trial (51). About 18,000 participants selected on the basis of a moderately elevated C-reactive protein (CRP) were distributed randomly into two groups: one was treated with a placebo, and the other with rosuvastatin. The primary hypothesis was to test rosuvastatin against placebo. An implicit additional objective was to test whether CRP levels could serve as indicators for the prescription of a cholesterol-lowering drug, even in patients with normal or even low blood cholesterol levels. JUPITER was therefore supposed to demonstrate that rosuvastatin is indicated in a specific "new" category of patients, i.e., those with slightly raised CRP levels (59-61).

As the main investigator of JUPITER also holds part of the license for the CRP assay kit - the other owner being a major Boston hospital - this additional objective implies that very serious conflicts of interest were present $(51,59)$.

What happened with JUPITER? The whole story has been told in several articles and book chapters $(50,51,59-61)$. Briefly, by the end of 2007, the investigators and the sponsors announced highly favorable results for rosuvastatin and that the trial should be discontinued $(50,51)$. According to them, it would have been unethical to leave millions of potential patients without treatment when they had already demonstrated the highly significant protective effect of rosuvastatin, notably on cardiovascular mortality (59-61). Accordingly, in March 2008, a press release announced the discontinuation of the JUPITER trial, with an average followup of less than 2 years per patient (59-61). The adequacy of this premature discontinuation was strongly challenged (59-61) but was ultimately confirmed by a committee supposedly "independent from the sponsor." 


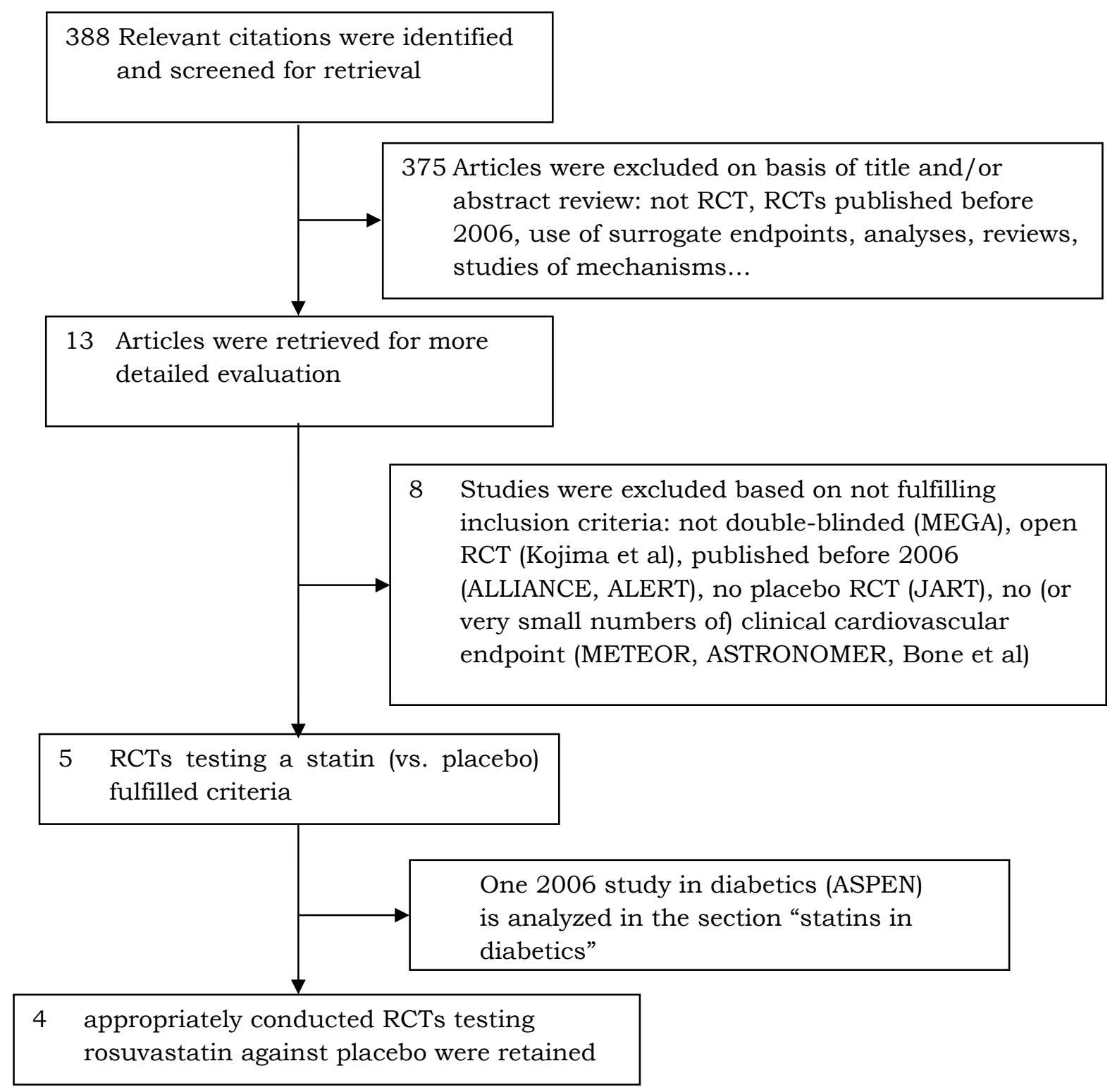

Figure 1. Flow diagram of selection of statin RCTs published after 2005/2006.

In November 2008, the results of JUPITER were published (51) and controversy grew further as many realized that the mortality data were not presented correctly. Criticisms abounded, triggering numerous answers and counterattacks from the investigators (5961). As the debate progressed, new data (previously unreleased) were reported by the investigators and/or the sponsor, surprisingly accompanied by modifications of the survival curves (59-61). This finally resulted in at least five different versions of cardiovascular mortality data being reported (59-61), which obviously is just as unacceptable as was the modification of the survival curves.
Ultimately, cardiovascular mortality was not judged different in the placebo and rosuvastatin groups, and the small difference in overall mortality (Table 2) was not validated by the statisticians of the FDA (59-61). As the raw clinical data, detained by the sponsor, are not available to independent experts and have not been examined by the FDA experts, it remains however impossible to make any definite conclusion regarding the true effectiveness of rosuvastatin in JUPITER. Admittedly, the lack of effect on death rate and the existence of mortality data misreporting do not necessarily question the effectiveness of rosuvastatin against nonlethal 
complications. An answer is however indirectly given by the three other trials testing rosuvastatin - CORONA, GISSI-HF, and AURORA - that did not report any effect on nonlethal complications (52-54).

Was the premature discontinuation of JUPITER a deliberate form of misreporting? The investigators must have been aware that they would be criticized for this as many scientists consider that when RCTs are stopped early for benefit, they usually show implausibly large treatment effects $(62,63)$. So what could have been the true reason motivating the decision for this methodological flaw in JUPITER? The answer might lie with the unexpected significant increase of new cases of diabetes in the rosuvastatin-treated patients.

The investigators tried to minimize this finding in 2008 (51) and later, claiming that "the cardiovascular and mortality benefits of statin therapy exceed the diabetes hazard" (64). They wrongly seem to support the idea that the only consequence of diabetes is cardiovascular complications, forgetting that type 2 diabetes increases the risk of many noncardiovascular diseases, such as cancers, eye and kidney diseases, dementia and cognitive decline, depression, and bone damage among many others (65-70). This statin-diabetes issue is further discussed below in the Safety section.

\section{The CORONA and GISSI-HF trials}

In the CORONA trial, over 5,000 AMI survivors aged 60 years or more were randomized to receive either a placebo or rosuvastatin (52). Despite a striking reduction in blood cholesterol levels, patients taking rosuvastatin had no clinical benefit whatsoever, particularly in terms of survival (Table 2). The occurrences of cardiac death, AMI, and other nonlethal ischemic complications were unambiguously not different between the two groups.

CORONA came in complete opposition to previous post hoc analyses of RCTs and also meta-analyses (71-73), all claiming that statins have beneficial effects on several endpoints, including mortality and nonlethal complications, in patients with post-AMI cardiac dysfunction and chronic heart failure with or without coronary heart disease.

Table 1. List of the main RCTs discussed in this review in the order of appearance in the text

\begin{tabular}{|l|l|l|l|l|}
\hline RCT acronym & Tested hypothesis & $\begin{array}{l}\text { Publication } \\
\text { year }\end{array}$ & $\begin{array}{l}\text { Significant } \\
\text { difference } \\
\text { for CV } \\
\text { mortality }\end{array}$ & $\begin{array}{l}\text { Reference } \\
\text { number }\end{array}$ \\
\hline JUPITER & Rosu vs. placebo & 2008 & No & 51 \\
\hline CORONA & Rosu vs. placebo & 2007 & No & 52 \\
\hline GISSI-HF & Rosu vs. placebo & 2008 & No & 53 \\
\hline AURORA & Rosu vs. placebo & 2009 & No & 54 \\
\hline 4S & Simva vs. placebo & 1994 & Yes & 74 \\
\hline 4D & Ator vs. placebo & 2005 & No & 77 \\
\hline SHARP & Simva + Eze vs. placebo & 2011 & No & 80 \\
\hline SATURN & Rosu vs. Ator & 2011 & NA* & 82 \\
\hline MIRACL & Ator vs. placebo & 2001 & No & 83 \\
\hline HPS & Simva vs. placebo & 2002 & Yes & 88 \\
\hline IDEAL & Simva vs. Ator & 2005 & No & 89 \\
\hline SEARCH & Simva 80 vs. Simva 20 & 2011 & No & 91 \\
\hline PROVE IT-TIMI 22 & Ator vs. Prava & 2004 & No & 92 \\
\hline CARDS & Ator vs. placebo & 2004 & No & 122 \\
\hline ASPEN & Ator vs. placebo & 2006 & No & 123
\end{tabular}

NA, "not applicable;" Rosu, rosuvastatin; Simva, simvastatin; Ator, atorvastatin; Prava, pravastatin; Eze, ezetimib. 
Table 2. Summary of mortality data in the 4 rosuvastatin RCTs

\begin{tabular}{|l|l|l|}
\hline RCT acronym & \multicolumn{1}{|c|}{ Placebo } & \multicolumn{1}{c|}{ Rosuvastatin } \\
\hline JUPITER & Cardiovascular mortality & $12^{*}$ \\
\hline CORONA & $12^{*}$ & 488 \\
\hline GISSI-HF & 487 & 478 \\
\hline AURORA & 488 & 324 \\
\hline Total & 324 & 1302 \\
\hline & 1311 & $198^{* *}$ \\
\hline JUPITER & \multicolumn{1}{|c|}{ Overall mortality } & 728 \\
\hline CORONA & $247^{* *}$ & 657 \\
\hline GISSI-HF & 759 & 636 \\
\hline AURORA & 644 & 2219 \\
\hline Total & 660 & \\
\hline
\end{tabular}

*Calculated by the authors as the numbers were not provided by the JUPITER investigators (see text).

**Data not formerly validated by the FDA statisticians because of the premature termination of the trial (see text).

Explaining discrepant scientific data is a fundamental work of independent scientists. So how can we explain the discrepancy between CORONA and previous RCTs testing a statin in secondary prevention, such as the often-cited Scandinavian Simvastatin Survival Study (4S) trial (74) for instance?

Somewhat strangely, it has been said that the failure of CORONA to show any benefit of rosuvastatin was hardly surprising because there was no reason for the statin to protect "elderly heart-failure" patients. According to these post hoc interpretations, a statin is supposed to prevent ischemic heart attacks, certainly not to extend the life of elderly patients with ruined hearts by stopping the progression of cardiac dysfunction.

The analysis of CORONA outcomes shows that this argument is not valid: most deaths occurred during a recurrent AMI and only a minority because of progression of heart failure (52). This is no surprise as previous studies have shown that recurrent AMI is the first cause of death following a prior AMI with cardiac dysfunction (75). CORONA was therefore clearly a study of the efficacy of a statin in preventing a recurrent AMI, i.e., a secondary prevention RCT (52).

Finally, when the authors analyzed their results, there was no difference when comparing patients according to age or degree of cardiac dysfunction at baseline: the youngest did not benefit any more than the oldest, and those who suffered from minor or no symptoms of heart dysfunction were no more protected than the most severe cases (52).

This was reinforced when Italian investigators reported the results of the GISSI-HF trial where approximately $50 \%$ of the patients recruited had very similar characteristics to the CORONA population (except that they were younger) and where again no benefit (Table 2) was demonstrated in the rosuvastatin group (53).

It is pointless to discuss the GISSI-HF results in detail, although it was a remarkable piece of clinical research. All one needs to say is that, like CORONA, GISSI-HF failed to show any benefit of cholesterol-lowering with a statin in secondary prevention.

\section{The AURORA trial in chronic kidney disease}

In the AURORA trial, rosuvastatin was tested against placebo in patients with severe chronic kidney disease, some of them with a previous AMI or other cardiac ischemic syndromes, thus again in secondary prevention [54].

Renal failure patients being at high risk of AMI, the expected benefit from lowering 
their cholesterol level has also been considered as very high. Indeed, for years, on the basis of meta-analyses using weak data extracted from studies not designed to primarily test the effectiveness of statins on renal failure patients (76), these patients (and their doctors) were misled into believing that their cholesterol level should be lowered as much as possible (50).

So what did AURORA show? The results were the same as in CORONA: no clinical benefit at all - for both fatal and nonfatal complications (Table 2) - despite a striking reduction in blood cholesterol (54).

AURORA put an end to the belief that cholesterol-lowering by a statin is useful in chronic renal failure. Actually, AURORA confirmed the negative results of a previous RCT named 4D (for the "German Diabetes and Dialysis Study Investigators") (77), which had tested the effects of atorvastatin in similar kidney failure patients.

AURORA and 4D underline that we should only trust results of individual studies that do respect the strict methods of RCTs based on a well-defined primary hypothesis $(37,38$, 50). Evidently, the same goes for metaanalyses $(50,55-58,62,63,71-73,76)$ in which flawed studies are very often included. And indeed, investigators still recently published new meta-analyses mixing wellconducted RCTs (such as AURORA and 4D) with a myriad of commercial studies reporting secondary endpoints or post hoc data $(78,79)$, resulting in the curious claim that statins might be useful in chronic renal failure patients.

The inadequacy of such methods is evidenced by the fact that the results differed. One meta-analysis claimed that statins reduce the risk of cardiovascular complications in patients with chronic kidney disease, including those receiving dialysis (78), while another concluded that there was no effect in patients on dialysis (79). One meta-analysis showed no effect of statins on stroke (78), while the other concluded that statins did reduce stroke in patients not on dialysis (79). Such metaanalyses should be discarded.

Also discarded by physicians should be the SHARP trial testing intense cholesterol- lowering (with simvastatin plus ezetimibe) in patients with chronic kidney disease and published in 2011, after the implementation of the New Regulations (80). In SHARP, there was no significant effect on coronary death, nonfatal AMI, any major coronary event, and all-cause death. The significant effect on the composite endpoint called "total cardiovascular events" (619 events in the placebo group vs. 526 in the simvastatin plus ezetimibe group) was almost totally the consequence of the between-group difference in the revascularization procedures (352 vs. 284) (80). As discussed $(42,50,60)$, revascularization is not a complication but a medical decision - easily biased by unblinding (43) and awareness of patient allocation - and can at best only be considered as a very soft endpoint. It cannot serve to judge the efficacy of any medicine to prevent cardiovascular disease. Finally, the trial was also criticized because of a lack of clarity in the statistical analysis plan (81).

Thus, physicians should conclude that cholesterol-lowering with a statin - or a combination of a statin with ezetimibe does not protect their patients with chronic kidney disease.

\section{Summary on recent (post-2005/2006) statin RCTs}

Data regarding cardiovascular and overall mortality in the four rosuvastatin RCTs are summarized in Table 2. The only conclusion can be that, taken as a whole, the four RCTs testing rosuvastatin - all conducted or published after the implementation of the New Regulations show that cholesterol-lowering with that specific statin is not proven to be effective, whether in primary or in secondary prevention. This is in total contradiction with the commercial RCTs published before the New Regulations.

The next question is then obvious: if rosuvastatin has not been proven effective, what about the statins tested in those "ancient" studies and that are allegedly remarkably effective on clinical outcomes while being less effective than rosuvastatin in lowering cholesterol?

Alternately, for the physicians in charge of fragile patients, the question is: "should I 
prefer another statin to protect my patients or, all the statins being equal, should I forget all the statins?"

\section{Are "ancient" statins better than rosuvastatin?}

\section{Atorvastatin}

A few studies comparing statins head to head are available (Table 1).

The SATURN or "The Study of Coronary Atheroma by Intravascular Ultrasound: Effect of Rosuvastatin versus Atorvastatin" trial, published in 2011 and thus supposedly conducted according to the New Regulations, compared the effects of rosuvastatin to those of atorvastatin, unfortunately in the absence of a control (placebo) group (82). The primary endpoint was the progression of atherosclerotic plaque, claiming that plaque volume - measured with sophisticated imaging techniques - is predictive of cardiovascular complications. The number of patients was relatively small (about one thousand), and the duration of the follow-up was quite short (2 years).

The results showed no significant difference between the two statins regarding the evolution of plaque volume during followup, which was curiously interpreted as showing that both statins were equally effective in slowing down the plaque evolution, when there was no control group (82). In addition, there was no difference in the number of major cardiovascular complications: 49 on atorvastatin versus 52 on rosuvastatin (82). One could argue that the trial was short and the number of patients too low to expect any significant difference to emerge between both the groups. However, the total lack of difference (not even a trend) after 2 years does not raise hope that, even with many more patients, atorvastatin would suddenly recover the remarkable effects it had boasted in the RCTs conducted and reported before the New Regulations.

Thus, according to SATURN, atorvastatin is not better than rosuvastatin and, as the latter is ineffective $(50-54,59-61)$, this raises serious doubts about atorvastatin efficacy. However, one has to consider the limitations of SATURN, in particular the small sample size. We therefore chose to re-evaluate the results of another RCT testing atorvastatin against placebo in secondary prevention: the Myocardial Ischemia Reduction with Aggressive Cholesterol Lowering (MIRACL) trial published in 2001 and often presented as an unambiguous demonstration that atorvastatin is effective to prevent cardiovascular complications $(83,84)$.

Why come back on MIRACL in 2015? The MIRACL trial is quite typical of the commercial RCTs undertaken long before the 2005 New Regulations. MIRACL compared atorvastatin ( $80 \mathrm{mg}$ ) to a placebo in over 3,000 patients who had just suffered an AMI, within 24 hours to 4 days after their admission to hospital. The investigators wished to demonstrate that the protective effect of large doses of atorvastatin was close to immediate. Importantly, the trial was totally controlled by the sponsor, to the point that even the main statistician of the study was a member of the sponsor staff (83).

The results were unambiguous: there were 68 deaths in the placebo group versus 64 in the atorvastatin group; 113 nonlethal AMIs in the placebo group versus 101 in the atorvastatin group; and 10 versus 8 cardiac arrests, respectively (83). The hypothesis that atorvastatin may protect from recurrence in secondary prevention should therefore be rejected without any hesitation, confirming our conclusions made from SATURN. However, MIRACL was $(83,84)$ - and still today (85) is presented as an unequivocal demonstration that a statin - in particular atorvastatin - should be imperatively prescribed in secondary prevention.

How was this surprising conclusion reached? The procedure was subtle. A new clinical cardiac endpoint category was added, in place of AMI or unstable angina. In their own words, the new category was "recurrent symptomatic myocardial ischemia with objective evidence requiring emergency hospitalization" (83). These patients were not suffering from AMI or unstable angina according to established criteria but of something else, i.e., emergency hospitalization - an endpoint even softer than the revascularization endpoint 
(discussed above) - which can in no way be used to judge the efficacy of a drug in scientific medicine. Moreover, the validation of that endpoint totally depended on the data collected by field investigators who belonged to the sponsor's staff. By performing this curious validationclassification of a "new" endpoint, at last something appeared to be slightly different in the two groups: they recorded 130 and 95 of these types of "cardiac events," respectively, in the placebo and atorvastatin groups. No additional comment is needed.

The failure of statins to reduce the risk of recurrence and death in the early high-risk period following AMI or acute coronary syndromes - the worst phase in secondary prevention - has been confirmed since then in various meta-analyses $(86,87)$, thereby also confirming that MIRACL was a flawed trial. The only conclusion for physicians then is that evidence shows that neither rosuvastatin nor atorvastatin (even at high dose) is effective in secondary prevention.

\section{Simvastatin}

For years, millions of AMI survivors worldwide have been treated with simvastatin on the basis of one single trial, the $4 \mathrm{~S}$ trial. The findings were published in 1994 and showed significant effects with the reduction of both cardiac death and nonfatal complications (74).

The 4S trial is the one and only published RCT assessing the effect of simvastatin in the well-defined context of post-AMI prevention (74). One should note, however, that here again, the trial was conducted on the field by the sponsor's staff and that the main statistician of the trial belonged to the sponsor's staff (74), which would today be unacceptable.

One could argue that there is another RCT, the Heart Protection Study (HPS), where simvastatin was tested against placebo in high-risk people, as about $40 \%$ of the randomized patients reported a previous (undated) AMI (88). Involving over 20,000 adults, HPS was designed to test two distinct hypotheses. The first was to determine whether simvastatin might reduce cardiovascular complication and mortality rates. The second tested whether an antioxidant cocktail could have the same effect. Four groups of over 5,000 patients each made up the HPS trial: group 1 took simvastatin + placebo; group 2, simvastatin + antioxidants; group 3, placebo + placebo; and group 4, a placebo + antioxidants. Only the comparison between group 1 (statin only) and group 3 (placebo only) matters in the present review as comparison with antioxidants is not relevant here.

Combining the four groups in their analyses, the Oxford CTSU claimed that simvastatin reduced total mortality by $13 \%$ (relative risk reduction) and any vascular death by $17 \%$ (88). However, the results were given comparing all patients taking simvastatin, i.e., $50 \%$ of the cohort, with all patients taking placebo, whether they were also taking antioxidants or not.

In other words, we cannot determine from the results given, what the effect of simvastatin given alone was when compared to placebo given alone. Half of the patients were taking antioxidants with either simvastatin or placebo. To exclude any unplanned interaction, it is evident that the results from all four groups must be reported separately. This is a minimum requirement and failing to do so is suspect. All the more considering are the very large sample sizes ( $\mathrm{n}>5000$ in each group) and the follow-up of 5 years. Not complying with this requirement should raise suspicion that the comparison of simvastatin alone against placebo alone was not conclusive.

In view of this uncertainty about the efficacy of simvastatin, is there any indication that it is better than atorvastatin?

Simvastatin was compared to atorvastatin in a trial called Incremental Decrease in End Points Through Aggressive Lipid Lowering (IDEAL), published in 2005 (89), at a time when investigators and sponsors began to be very prudent, 2005 being right in the middle of the transition phase between the ancient and New Regulations. Briefly, in IDEAL, almost 9,000 patients with coronary heart disease were treated with either atorvastatin or simvastatin. The low-density lipoprotein (LDL)-cholesterol 
level was a bit lower in the high-dose atorvastatin group, but the $11 \%$ reduction in the primary endpoint (nonfatal AMI + cardiac death) in this group was not statistically significant (89). More specifically, there was no difference between groups in total death rates $(374$ vs. 366$)$ or in cardiac deaths (178 vs. 175$)$.

Thus, IDEAL shows that atorvastatin and simvastatin are not different in terms of clinical effectiveness over a period of nearly 5 years in secondary prevention (89). As atorvastatin is apparently ineffective in post-AMI patients - as seen in MIRACL (83) - simvastatin should be considered as ineffective too. It means that the $4 \mathrm{~S}$ results have never been confirmed.

As discussed in the Introduction section, reproducibility of scientific data is the cornerstone of their credibility $(31,32)$. As long as we do not have access to the raw clinical data of HPS and 4S - and because the methods used in both RCTs are questionable (in particular, the lack of independent statistical analyses in 4S) - it seems to the least prudent to consider HPS and $4 \mathrm{~S}$ as doubtful RCTs. The lack of effect of simvastatin in secondary prevention has been indirectly confirmed in the Study of the Effectiveness of Additional Reductions in Cholesterol and Homocysteine (SEARCH) trial, comparing intensive simvastatin regimen with a four-time lower simvastatin dosage, as discussed in the next section.

\section{Is intensive statin regimen more effective?}

It has been claimed that more-intense versus less-intense statin regimen is more effective to reduce cardiovascular complications (90). Is there any difference between the "ancient" and the recent RCTs in this respect?

Only one RCT investigating intensive cholesterol-lowering with a statin alone has been published after the 2005/2006 transition period; it is the $\mathrm{SEARCH}$ trial comparing $80 \mathrm{mg}$ versus $20 \mathrm{mg}$ of simvastatin in a huge ( $\mathrm{n}=12,064)$ population of AMI survivors (91). Results after a mean follow-up of almost 7 years are by no way ambiguous: there was no significant difference between groups for any cardiovascular endpoint, including the very soft composite endpoint $(\mathrm{p}=0.10)$. More specifically, intense simvastatin regimen did not significantly reduce coronary death (447 vs. 439), major coronary events (1189 vs. 1225), stroke (255 vs. 279), or any death rate (964 vs. 970) (91). Neither the sample size nor the duration of follow-up could explain the failure.

Curiously, the Oxford CTSU investigators concluded that the SEARCH results "were consistent with previous RCTs" demonstrating that more intense statin therapy safely produces extra benefits (91). This is obviously wrong and raises major concerns about the review process in some medical journals, as well as about the credibility of the Oxford CTSU studies.

Another interesting study (although published in 2004), the Pravastatin or Atorvastatin Evaluation and Infection Therapy-Thrombolysis in Myocardial Infarction 22 (PROVE IT-TIMI 22) trial, is worthwhile to examine. The trial tested whether aggressive lipid-lowering using atorvastatin $80 \mathrm{mg} /$ day provided greater protection against death or major cardiovascular events than did moderate lipid-lowering using pravastatin $40 \mathrm{mg} /$ day [92]. More than 4,000 patients were recruited a median of 7 days after AMI and followed up for 2 years.

Importantly, the trial - whose results were published before the 2005/2006 New Regulations - tested several hypotheses (as in HPS), with a second randomization to allocate patients to groups receiving either an antibiotic or a placebo. As discussed above, testing two hypotheses in the same patients is not a good procedure as interactions are liable to contaminate each comparison.

The antibiotic part of PROVE IT-TIMI 22 was unfortunately reported in a separate article (93). This is a situation where providing the results of all 4 trial groups is essential but was not done in PROVE ITTIMI 22, representing a source of bias. LDL-cholesterol levels were decreased by $49 \%$ in the atorvastatin group and $21 \%$ in the pravastatin group.

Curiously, all clinical data are only expressed as percentages. We can however make some calculations and obtain 
approximate absolute numbers. The authors announce a reduction of $28 \%$ for total mortality and of $30 \%$ for cardiac mortality, which seems quite impressive but that are nonsignificant. Moreover, as shown in Figure 4 of the article (92) indicating the 2-year event rates (page $1501)$, the mean risks of dying were, respectively, $2.2 \%$ and $3.2 \%$ and the risk of cardiac death were $1.1 \%$ and $1.4 \%$. In other words and making the story short, we can calculate that, in fact, there were something like 18 versus 22 cardiac deaths for 1,600 patients after 2 years, a difference of four deaths. In other words, a minute difference in absolute Figures was disguised as a "30\% reduction in the risk of cardiac death" in PROVE IT-TIMI 22.

Using the same calculations, we found 55 nonfatal AMIs in the atorvastatin group and 59 in the pravastatin group, an obviously nonsignificant between-group difference. No additional comment is needed, and we can safely conclude that pravastatin is not better than atorvastatin, and vice versa.

\section{Summary of the studies comparing statin versus statin}

In short, rosuvastatin (which is not effective) is not different from atorvastatin, which, itself, is not different from simvastatin and pravastatin (see Table 1). This leads to the conclusion - based on the comparison of statin versus statin - that the early statins (simvastatin, pravastatin, and atorvastatin) are not different from the most recent one (rosuvastatin). Thus, cholesterol-lowering with any of these medicines yields no detectable benefit against cardiovascular complications, in particular cardiac death and nonfatal AMI, and no effect on the overall mortality.

This lack of difference between the early and new statins - as examined in face-toface RCTs - was recently and indirectly supported by a very large cohort study based on the huge French national health insurance database comparing the cardiac and cerebrovascular prognosis of 106,941 patients prescribed rosuvastatin with 56,860 patients prescribed simvastatin, the average follow-up being 36 months (94). No difference between the two statins was observed in this real-life study, suggesting again that the lack of significant protective effect of rosuvastatin may represent the true effect of statins in general.

Finally, the observed discrepancy between "historic" statin RCTs and post-2005/2006 statin RCTs - not considering the studies comparing statin versus statin - implies that mixing data from these two categories of RCTs in meta-analyses should no longer be accepted. On the contrary, to be credible, any new meta-analysis should separately analyze RCTs conducted before and after the implementation of the 2005 New Regulations.

However, this analytical strategy is facing a major problem: the clinical heterogeneity of the patients included in the four rosuvastatin RCTs published after 2005/2006. Clinical homogeneity is the cornerstone of consistent and credible meta-analysis as seen by medical doctors. Mixing healthy people with AMI survivors (and more or less severe cardiac dysfunction), chronic heart failure patient, and chronic kidney failure patient in the same data set is scientific nonsense.

\section{The statin safety issue}

The statin safety issue is becoming a major problem as - according to the Oxford CTSU, CTT consortium, and even the Cochrane collaboration (5) - experts did not seriously examine (and report) statin adverse effects in commercial RCTs and in the meta-analyses, notably in those combining data from up to 27 statin RCTs (12-15). This raises trust issues: how can we continue to trust experts who have so long claimed that statin prescription resulted in major benefits without any evidence of emerging hazards?

To illustrate the point, we chose two examples - the thromboembolism and diabetes issues - because they are very important for medical doctors who must systematically evaluate the benefit/harm balance of any treatment before prescribing.

\section{Statins and thromboembolisms}

Do statins decrease thromboembolism risk? 
This example brings us back to the JUPITER trial (51). Despite the premature termination of the trial and that thromboembolism was not a primary endpoint - both facts considerably increasing the possibility of a chance effect and biased results - JUPITER investigators nonetheless claimed that rosuvastatin significantly reduces the occurrence of symptomatic venous thromboembolism (95). One should note that the absolute reduction was $0.14 \%$ (!) and that no reduction in pulmonary embolism was observed. This is already enough not to attach any importance to the findings, as confirmed by a subsequent meta-analysis (96), which analyzed published and unpublished results of statin RCTs including JUPITER. It was found that statins do not significantly reduce the risk of venous thromboembolism: events occurred in $0.9 \%$ of the participants who were given statins and in $1 \%$ of the participants who were given placebo. The whole issue strongly indicates (as expected) that JUPITER results about thromboembolism happened by chance.

Until we get new and consistent data, the theory that statins may have some anticoagulant properties should be rejected.

\section{Statins and new-onset diabetes}

Whether statins induce new-onset diabetes is a major question because diabetes is a serious disease with many cardiovascular and noncardiovascular complications, including kidney diseases, eye diseases, and also cancers.

In fact, they do. Curiously, it is only with the JUPITER trial in 2008 that the statindiabetes issue was revealed (51) and, as discussed above, it might have been a major reason to prematurely stop JUPITER. It took 4 additional years before the FDA sent out a warning (97).

This means that it took at least 30 statin RCTs and 30 years - during which the statins were fully prescribed - to bring to light this toxic effect. The whole story seems to be a remarkable illustration of high bias in the reporting of harmful outcomes within the company-sponsored
RCTs $(98,99)$. In fact, statins not only increase the risk of de novo diabetes but even more frequently increase insulin resistance and metabolic syndrome, probably through their toxic effect (at least in part) on skeletal muscles (100).

Nevertheless, the investigators who had not seen (or reported) anything until then, immediately reacted by claiming that we must not change anything in our way of prescribing statins (101-103). Their "reasoning" was (and still is) that as statins are highly effective in preventing AMI and stroke in diabetics, becoming a diabetic is not a problem as the patient would ultimately anyway be protected from cardiovascular problems (101-103). Should physicians trust such an advice?

While probably untrue in itself $(104,105)$, this reasoning does in addition not take into consideration the several complications of diabetes that statins cannot reduce or may even stimulate $(50$, 60, 65-70, 106-113). And physicians must remember that the vast majority of patients prescribed a statin are in fact at low risk of AMI or stroke.

On one hand, even if statins were really protective against AMI and stroke - an elusive theory as we have shown - only a very small proportion of the treated patients would benefit $(7,9)$. On the other hand, among the huge number of low-risk patients treated with statins, a significant proportion (see below) will become diabetic or insulin-resistant and suffer complications from this - including noncardiovascular complications. If we then add to this the other deleterious side effects of statins (106-117), which have been systematically misreported or underestimated, the whole issue is of major importance.

Putting data from company-sponsored RCTs aside, a crucial question for physicians (and their patients) remains: what is the true pro-diabetic effect of statins? In a real-world setting, the risk of new-onset diabetes has been reported to increase with dose regimen and as adherence with statin treatment increases; the relative risk increase of new-onset diabetes may reach 40 to $70 \%(118-121)$. 
Do statins prevent cardiovascular complications in diabetics?

This then becomes a major issue for the treating physicians. Let us first cautiously have a look at the existing data as some statin experts are claiming that statins do prevent cardiovascular complications in diabetics (101-103), whereas others say the opposite $(104,105)$.

To stay in line, only robust data should be retained. For that reason, we have conducted a MEDLINE search to specifically identify double-blinded RCTs testing a statin against placebo in diabetic patients. Studies comprising secondary and subgroup analyses were excluded because a posteriori analysis based on subgroups extracted from previous unblinded trials is open to major bias. Results of our MEDLINE search are summarized in Figure 2 and Table 1.

How many RCTs have tested the effects of statins in diabetics as a primary hypothesis? There are three RCTs, namely Collaborative Atorvastatin Diabetes Study (CARDS) (122), Atorvastatin Study for Prevention of Coronary Heart Disease Endpoints in noninsulin-dependent diabetes mellitus (ASPEN) (123), and 4D (77). Despite the fact that these three RCTs did not show unambiguous benefits of statins in diabetics, some statin experts (124) claimed the opposite. So, let us carefully examine the data.

633 Relevant citations were identified and screened for retrieval

613 Articles were excluded on basis of title and/or abstract review: not RCT, use of surrogate endpoints, analyses, reviews, commentaries, studies of biological mechanisms...

20 Articles were retrieved for more detailed evaluation

17 Studies were excluded based on not fulfilling inclusion criteria: not double-blinded, open RCT, secondary analysis, diabetics included as nonrandomized subgroups

$3 \quad$ RCTs in diabetics testing a statin (vs placebo) fulfilled criteria: 4D, ASPEN and CARDS

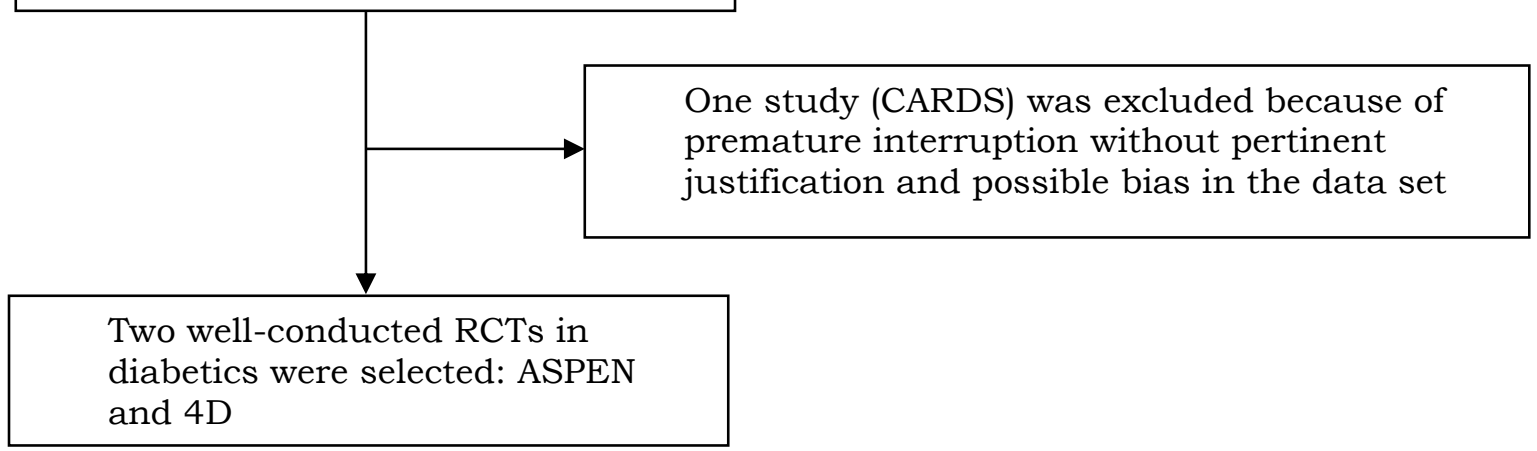

Figure 2. Flow diagram of selection of statin RCTs testing a statin against placebo in diabetic patients. This an extension of a systematic review published in 2012 (104). Inclusion and exclusion criteria are the same as those used in our previous systematic review (104), with a special attention to studies reporting secondary and subgroup analyses. 
In brief, 4D is a RCT testing atorvastatin against placebo (median follow-up 4 years) in 1,255 diabetics receiving maintenance hemodialysis (77). There was no significant difference between the two groups for the primary endpoint (relative risk 0.92) and for total mortality (relative risk 0.93). The risk of fatal stroke was significantly increased among patients receiving atorvastatin (relative risk 2.03).

The only possible conclusion of 4D should have been that the statin did not protect diabetics (77). The investigators actually concluded that "initiation of statin therapy in patients with diabetes who already have end-stage renal disease may come too late to translate into consistent improvement of the cardiovascular outcome" (77).

Curiously, in a subsequent substudy of 4D however - reanalyzing the data set and making an a posteriori subgroup analysis, thereby drastically increasing a chance effect - they claimed that "in patients with type 2 diabetes mellitus undergoing hemodialysis, atorvastatin significantly reduces the risk of fatal and nonfatal cardiac events and death from any cause if pre-treatment LDL-cholesterol is >145 $\mathrm{mg} / \mathrm{dl}$ " (125). This is simply not scientifically acceptable and, once again, shows that subgroup and secondary analyses contradicting the results of the tested primary hypothesis should not be retained.

The failure of 4D to show a protective effect of atorvastatin in diabetics receiving maintenance hemodialysis is supported by the results of another RCT in patients with hemodialysis, the AURORA trial (54) discussed above, in which rosuvastatin also failed to protect against cardiovascular complications.

Nonetheless, the comment made by the 4D investigators in their first original report (77) - lack of benefit because of too late initiation of treatment - might be relevant. It has been examined in ASPEN, an RCT where diabetics with severe renal dysfunction were excluded (123).

The ASPEN trial investigated the cardiovascular effects of atorvastatin in diabetics, with or without documented coronary heart disease (CHD) (123). The trial was originally designed as a secondary prevention trial but updates in treatment guidelines for individuals with CHD impaired recruitment. The protocol was therefore amended to enroll subjects without prior CHD (123).

Following the new statistical calculations, the trial was powered to detect differences between the statin and the placebo groups but not to detect differences in the primary or secondary prevention subgroups alone (104). Subjects were followed up during 4 years.

There was no significant difference between groups for the primary endpoint (166 and 180 events for the atorvastatin and the placebo group, respectively), for cardiovascular mortality (38 and 37 deaths), and overall mortality (70 and 68 deaths). Thus, the results of ASPEN were similar to those of 4D but in the absence of severe renal dysfunction. The extension of criteria for enrollment was likely not an important cause of bias because the statistical protocol was amended accordingly.

The two trials complement each other: in 4D (diabetics with severe renal dysfunction), patients were at very high risk, while in ASPEN patients were at rather low risk. In both RCTs, we see no effect of cholesterol-lowering with atorvastatin.

In CARDS, the third RCT testing atorvastatin against placebo, 2,838 diabetic patients were included (122). In contrast to ASPEN and 4D, significant reduction of a composite primary endpoint was reported (relative risk 0.63). However, the numbers of primary endpoints in CARDS were small (83 and 127 in the statin and placebo group), despite the fact that the investigators used a composite primary endpoint mixing hard and soft (such as revascularization) events. This criticized strategy considerably increases the probability of a chance effect (42). Indeed, there was no statistically significant difference for all-cause mortality and coronary mortality in CARDS.

In this context, the decision of early termination -2 years before the anticipated 
end without a clear explanation - was unjustified. Also, the clinical inconsistencies seen in CARDS suggest that the validation and classification of the endpoints were questionable. And finally because, as written by the investigators, "site monitoring, data collection, and data entry was done by sponsor's staff” (122) the possibility of outcome misreporting in CARDS must be considered. Clearly, it was ethically and scientifically indicated to continue the trial to definitely clarify the effect on cardiac and total mortality.

The CARDS trial has to be suspected of being biased until confirmed by other trials. No such confirmation has occurred.

On the contrary, both 4D and ASPEN failed to report any benefit (not even a trend toward benefit) of atorvastatin in diabetics $(77,123)$.

Taken together, the three RCTs testing a statin in diabetics as a primary hypothesis failed to show any benefit.

\section{Summary of the statin-diabetes issue}

Despite the absence of evidence, why do the "official" recommendations still state that most diabetics (if not all) should be treated with cholesterol-lowering drug $(126,127)$ ?

One explanation is that these recommendations are usually based on meta-analyses that are supposed to objectively synthetize the whole scientific knowledge about the issue. In fact, even meta-analyses examining whether statins may protect diabetics do not all show the same results. For instance, Chang et al. (105) concluded in 2013 that no significant benefit of statin is found in primary $(\mathrm{p}=$ $0.24)$ as well as in secondary $(p=0.26)$ prevention of cardiovascular complications in diabetics whereas Collins, his Oxford CTSU colleagues, and the CTT's Collaborators concluded that statins reduce the risk of AMI in diabetics, even stating that "statin should be considered for all diabetics" (124).

How can we explain such discordant conclusions?

The CTT meta-analysis pooled in 2008 the data from 14 statin RCTs but none of the statin RCTs published after 2005 was included thereby curiously excluding 4D (77) and ASPEN (123). Moreover, among the 14 included RCTs, only one - CARDS (122) for which we have exposed the major methodological problems - prospectively randomized diabetic patients and thus actually tested the effect of a statin in diabetics as a primary hypothesis.

Data from the other 13 trials were from nonrandomized subgroups of diabetics representing between $1 \%$ and $35 \%$ of the total of the patients enrolled in each trial (124) - and therefore open to major bias. Even more surprisingly, 4D and ASPEN although not included in the main analysis - were mentioned at the end of the discussion section of the CTT report, the authors writing that "their conclusions are not materially affected by the results of ASPEN and 4D trials" (124).

On the contrary, true science imposes to only consider statin RCTs where diabetics were prospectively randomized - namely CARDS, 4D, and ASPEN - as Chang et al. (105) did, rather than partial retrospective data from nonrandomized subgroups of diabetics. The CTT meta-analysis is therefore flawed by a major selection bias (124).

\section{Limitations of this analysis}

The main limitation of the present study is that we do not have free access to the raw data of the many RCTs we are discussing. The lack of transparency of commercial RCTs - i.e., the impossibility of verifying the way the clinical data are collected, the data sets are constituted, cleaned and digitized, and the way statistical analyses are conducted - definitively limits our ability to evaluate the accuracy of the published data.

Even if we can suspect the existence of problems in some RCTs - JUPITER, HPS, MIRACL, and many others not mentioned in the present article - raw data remain in the darkness. This is a major problem for medical doctors who must make a decision (prescription or not) every day.

So despite advances in clinical research and RCT transparency, there are still scientists and regulators - the EMA for instance (29) - 
saying that the present regulations are not sufficient and should be reinforced (30). Obviously, full access to raw RCT data (still not possible) would allow independent researchers to examine the risks and benefits of medical drugs and thereby counterbalance the industry's power to assess its own products in the "industry-sponsored" RCTs.

Clearly, legitimate interests in the protection of private (industry) investments must be weighed against other legitimate interests, such as the benefit and the protection of patients. The right balance between these interests is an obvious duty for all stakeholders involved, including regulators. And truly, when industry investments have been paid back, years after publication of RCTs that justified the marketing of a new medicine, there is no reason remaining not to give free access to RCT raw data unless, of course, there are things that are not to be shown.

\section{Conclusions}

A careful examination of the most recent statin RCTs (Table 2), followed by comparing statins to each other, clearly shows that contrary to what has been claimed for decades, statins do not have a significant effect in primary and secondary prevention of cardiovascular disease. One of the major lessons of the rosuvastatin RCTs was to confirm that only RCTs testing clearly defined primary hypotheses - and only a primary hypothesis $(38,50)$ - can provide a reliable evaluation of the efficacy of any medical drug. As a consequence, the well-spread theory, based on ancient RCTs, that statins are unambiguously protective in secondary prevention should be discussed in the light of more robust data provided by more recent and more credible RCTs.

Regarding the statin-diabetes issue, for instance, the only possible interpretation based on robust data is that statins do not protect the diabetics, while there is no question about their diabetogenic effect. It is high time to re-assess the whole statinsdiabetes issue. In our opinion - built on evidence-based medicine - and in contradiction with official recommendations, medical doctors should not prescribe statins in diabetics and in patients with metabolic syndromes.
As for statin safety, we are facing a major problem after the official admission that we lack the data (5). For medical doctors, this is unacceptable as their prescriptions must be based on a right evaluation of the benefit/harm balance of any medical drug.

We must enter a new era of full access to raw data from industry-sponsored RCTs $(20,21)$. This is the only way to allow transparency and to restore the credibility of clinical research. It is time to require the implementation of completely reliable methods to conduct medical trials so as to restore mutual confidence between all participants in the patient's care (22-24).

The 2005/2006 New Regulations definitely represented a step in the right direction (4650), but it nevertheless remains that investigators and industrials can still succeed in finding a way around them. Indeed, since 2006, the media in various countries report problems every week between the pharmaceutical industry (and the experts working with it) and the law courts (25-28).

This has led to the dogmas about statin efficacy and safety, based on unrealistic clinical reports and flawed meta-analyses, resulting in biased recommendations about statin use $(16,17,126,127)$ and ultimately extravagant situations and claims $(128,129)$.

The obvious final conclusion for physicians is that the present claims about the efficacy and safety of statins are not evidence-based.

\section{Competing interests}

None of the authors have any financial links with the pharmaceutical industry; Michel de Lorgeril discloses receiving research grants (through the Grenoble University School of Medicine) from the European Community and from the Barilla Inc.

\section{References}

1. Jefferson T, Jones MA, Doshi P, Del Mar $\mathrm{CB}$, Hama R, Thompson MJ, et al. Neuraminidase inhibitors for preventing and treating influenza in healthy adults and children. Cochrane Database Syst Rev. 2014;4:CD008965. 
http://dx.doi.org/10.1002/14651858.CD0 08965.pub4

2. Jefferson T, Doshi P. Multisystem failure: the story of anti-influenza drugs. BMJ. 2014;348:g2263.

3. Loder E, Tovey D, Godlee F. The Tamiflu trials. BMJ. 2014;348:g2630.

4. Seife C. Is drug research trustworthy? The pharmaceutical industry funnels money to prominent scientists who are doing research that affects its productsand nobody can stop it. Sci Am. 2012;307:56-63.

5. Statins expert calls for safety checks over the drug.

http://www.express.co.uk/news/uk/5582 49/statins-expert-heart-drug-rory-collins

6. Collins R. "Not for publication" Letter addressed to the BMJ Editors.

http://journals.bmj.com/site/bmj/statins /SP17\%20Letter\%201\%20from\%20Rory \%2 OCollins\%20to\%20FG\%20dated\%2031\%20 March\%20Not\%20for\%20Publication.pdf

7. Abramson JD, Rosenberg HG, Jewell N, Wright JM. Should people at low risk of cardiovascular disease take a statin? BMJ. 2013;347:f6123.

8. Sever P. The BMJ statins papers misrepresent the facts. BMJ. 2014;348:g4030.

9. Godlee F. Adverse effects of statins. BMJ. 2014;348:g3306.

10. Fahey T, Smith S. Retraction of statins article is not in the public interest: better characterisation of benefits and risks is crucial. BMJ. 2014;348:g4028.

11. Goldacre B, Godlee F, Heneghan C, Tovey D, Lehman R, Chalmers I, et al. Open letter: European Medicines Agency should remove barriers to access clinical trial data. BMJ. 2014;348:g3768.

12. Armitage J. The safety of statins in clinical practice. Lancet. 2007;370: 1781-90.

http://dx.doi.org/10.1016/S01406736(07)60716-8.
13. Armitage $\mathrm{J}$, Baigent $\mathrm{C}$, Collins $\mathrm{R}$. Misrepresentation of statin safety evidence. Lancet. 2014;384:1263-4.

http://dx.doi.org/10.1016/s01406736(14)61765-7.

14. Collins R. Lack of adverse effect of statin therapy on common muscle-related adverse events. Eur J Prev Cardiol. 2015;22:1066.

http://dx.doi.org/10.1177/204748731454 $\underline{1732}$

15. Cholesterol Treatment Trialists' (CTT) Collaborators, Mihaylova B, Emberson J, Blackwell L, Keech A, Simes J, et al. The effects of lowering LDL cholesterol with statin therapy in people at low risk of vascular disease: meta-analysis of individual data from 27 randomised trials. Lancet. 2012;380:581-90.

16. Stone NJ, Robinson JG, Lichtenstein AH, Bairey Merz CN, Blum CB, Eckel RH, et al.; American College of Cardiology/American Heart Association Task Force on Practice Guidelines. 2013 ACC/AHA guideline on the treatment of blood cholesterol to reduce atherosclerotic cardiovascular risk in adults: a report of the American College of Cardiology/American Heart Association Task Force on Practice Guidelines. J Am Coll Cardiol. 2014;63:2889-934.

http://dx.doi.org/10.1016/j.jacc.2013.11. $\underline{002}$.

17. National Institute for Health and Care Excellence: NICE clinical guideline no. 181. Lipid modification: cardiovascular risk assessment and the modification of blood lipids for the primary and secondary prevention of cardiovascular disease. July 2014.

http://www.nice.org.uk/guidance/cg181/r esources/guidance-lipid-modificationcardiovascular-risk-assessment-and-themodification-of-blood-lipids-for-theprimary-and-secondary-prevention-ofcardiovascular-disease-pdf.

Accessed November 10, 2015.

18. Godlee F. Statins and The BMJ. BMJ. 2014;349:g5038.

19. Diamond DM, Ravnskov U. How statistical deception created the appearance that statins are safe and effective in primary 
and secondary prevention of cardiovascular disease. Expert Rev Clin Pharmacol. 2015;8:201-10.

http://dx.doi.org/10.1586/17512433.201 $\underline{5.1012494}$

20. Doshi P, Goodman SN, Ioannidis JP. Raw data from clinical trials: within reach? Trends Pharmacol Sci. 2013;34:645-7. http://dx.doi.org/10.1016/j.tips.2013.10.006

21. Strom BL, Buyse M, Hughes J, Knoppers BM. Data sharing, year 1 - access to data from industry-sponsored clinical trials. N Engl J Med. 2014;371:2052-4.

http://dx.doi.org/10.1056/NEJMp1411794

22. Abbasi K. The missing data that cost \$20bn. BMJ. 2014;348:g2695.

23. Protecting citizens' health: transparency of clinical trial data on medicines in the EU. Available at:

http://haieurope.org/wp-

content/uploads/2013/10/HAI_Protectingcitizenshealth-transparency-of-clinicaltrial-data-on-medicines-in-the-EU.pdf.

Accessed November 20, 2015.

24. Protecting citizens' health. Available at: http://english.prescrire.org/en/79/207/4 6302/2612/2506/SubReportDetails.aspx. Accessed November 20, 2015.

25. Jefferson $T$, Jones MA, Doshi P. Neuraminidase inhibitors for preventing and treating influenza in healthy adults and children. Cochrane Database Syst Rev. 2012; 1:CD008965.

26. Heneghan CJ, Onakpoya I, Thompson $M$, Spencer EA, Jones M, Jefferson T. Zanamivir for influenza in adults and children: systematic review of clinical study reports and summary of regulatory comments. BMJ. 2014;348:g2547.

27. Nisen P, Rockhold F. Access to patientlevel data from GlaxoSmithKline clinical trials. N Engl J Med. 2013;369:475-8.

http://dx.doi.org/10.1056/NEJMsr1302541

28. Jain A, Nundy S, Abbasi K. Corruption: medicine's dirty open secret. BMJ. 2014;348:g4184.
29. Eichler HG, Pétavy F, Pignatti F, Rasi G. Access to patient-level trial data - a boon to drug developers. N Engl J Med. 2013;369:1577157-9.

http://dx.doi.org/10.1056/NEJMp1310771

30. Rabesandratana T. Drug watchdog ponders how to open clinical trial data vault. Science. 2013;339:1369-1370.

http://dx.doi.org/10.1126/science.339.61 $\underline{26.1369}$

31. McNutt M. Reproducibility. Science. 2014;343:229.

http://dx.doi.org/10.1126/science. 1250475

32. Collins FS, Tabak LA. Policy: NIH plans to enhance reproducibility. Nature. 2014;505:612-3.

33. Dwan K, Altman DG, Clarke M, Gamble C, Higgins JP, Sterne JA, et al. Evidence for the selective reporting of analyses and discrepancies in clinical trials: a systematic review of cohort studies of clinical trials. PLoS Med. 2014;11:e1001666.

http://dx.doi.org/10.1371/journal.pmed.1 $\underline{001666}$

34. Ebrahim S, Sohani ZN, Montoya L, Agarwal A, Thorlund K, Mills EJ, et al. Reanalyses of randomized clinical trial data. JAMA. 2014;312:1024-32.

http://dx.doi.org/10.1001/jama.2014.9646

35. Landewé RB. How publication bias may harm treatment guidelines. Arthritis Rheumatol. 2014;66:2661-3.

http://dx.doi.org/10.1002/art.38783

36. Wieseler B, Wolfram N, McGauran N, Kerekes MF, Vervölgyi V, Kohlepp P, et al. Completeness of reporting of patientrelevant clinical trial outcomes: comparison of unpublished clinical study reports with publicly available data. PLoS Med. 2013;10:e1001526.

http://dx.doi.org/10.1371/journal.pmed.1 $\underline{001526}$

37. Ioannidis JP. Why most published research findings are false. PLoS Med. 2005;2:e124.

http://dx.doi.org/10.1371/journal.pmed.0 $\underline{020124}$ 
38. Ioannidis JP. How to make more published research true. PLoS Med. 2014;11:e1001747.

http://dx.doi.org/10.1371/journal.pmed.1 $\underline{001747}$

39. Karha J, Topol EJ. The sad story of Vioxx, and what we should learn from it. Cleve Clin J Med. 2004;71:933-4, 936, 938-9.

40. Alpert JS. The Vioxx debacle. Am J Med. 2005;118:203-4.

http://dx.doi.org/10.1016/j.amjmed.2005. $\underline{01.020}$

41. Landefeld CS, Steinman MA. The Neurontin legacy - marketing through misinformation and manipulation. $\mathrm{N}$ Engl $\mathrm{J}$ Med. 2009;360:103-6.

http://dx.doi.org/10.1056/NEJMp0808659

42. Cordoba G, Schwartz L, Woloshin S, Bae H, Goetzsche PC. Definition, reporting and interpretation of composite outcomes in clinical trials: systematic review. BMJ. 2010;341:c3920.

43. Nguyen PV. Electronic health records may threaten blinding in trials of statins. BMJ. 2014;349:g5239.

44. Blendon RJ, Benson JM, Hero JO. Public trust in physicians - U.S. medicine in international perspective. $\mathrm{N}$ Engl $\mathrm{J}$ Med. 2014;371:1570-72.

http://dx.doi.org/10.1056/NEJMp1407373

45. Duncan Moore J. U.S. Physician Leaders Suffer Loss of Public Trust. Available at: http://www.medpagetoday.com/PublicHeal thPolicy/GeneralProfessionalIssues/48402. Accessed November 30, 2015.

46. New Clinical Trial Regulation. Available at:

http:/ /ec.europa.eu/health/files/eudralex /vol-1/dir_2005_28/dir_2005_28_en.pdf.

Accessed November 30, 2015.

47. Commission Directive 2005/28/EC of 8 April 2005 laying down principles and detailed guidelines for good clinical practice as regards investigational medicinal products for human use, as well as the requirements for authorization of the manufacturing or importation of such products. Official Journal of the European Communities L91: 13-19. Available at:

http://ec.europa.eu/enterprise/pharmaceu ticals/eudralex/vol-

1/dir_2005_28/dir_2005_28_en.pdf.

Accessed November 30, 2014.

48. Bollapragada SS, Norrie JD, Norman JE. Review of new regulations for the conduct of clinical trials of investigational medicinal products. BJOG. 2007;114:91721.

http://dx.doi.org/10.1111/j.14710528.2007.01415.x.

49. Hartmann M. Impact assessment of the European Clinical Trials Directive: a longitudinal, prospective, observational study analyzing patterns and trends in clinical drug trial applications submitted since 2001 to regulatory agencies in six EU countries. Trials. 2012;13:53.

http://dx.doi.org/10.1186/1745-6215-13$\underline{53}$

50. de Lorgeril M. Cholesterol and statins. Sham science and bad medicine. Vergèze, France: Thierry Souccar Publishing, 2014.

51. Ridker PM, Danielson E, Fonseca FA, Genest J, Gotto AM Jr, Kastelein JJ, et al.; for the JUPITER Study Group. Rosuvastatin to prevent vascular events in men and women with elevated C-reactive protein. N Engl J Med. 2008;359:2195207.

http://dx.doi.org/10.1056/NEJMoa0807646

52. Kjekshus J, Apetrei E, Barrios V, Böhm M, Cleland JG, Cornel JH, et al.; CORONA Group. Rosuvastatin in older patients with systolic heart failure. N Engl J Med. 2007;357:2248-61.

http://dx.doi.org/10.1056/NEJMoa0706201

53. Gissi-HF Investigators, Tavazzi L, Maggioni AP, Marchioli R, Barlera S, Franzosi MG, Latini $R$, et al. Effect of rosuvastatin in patients with chronic heart failure (the GISSI-HF trial): a randomised, double-blind, placebo-controlled trial. Lancet. 2008;372:1231-9.

54. Fellström BC, Jardine AG, Schmieder $\mathrm{RE}$, Holdaas H, Bannister K, Beutler J, et al. for the AURORA Study Group. Rosuvastatin and cardiovascular events in 
patients undergoing hemodialysis. N Engl J Med. 2009;360:1395-407.

http://dx.doi.org/10.1056/NEJMoa0810177

55. Baigent C, Keech A, Kearney PM, Blackwell L, Buck G, Pollicino C, et al; Cholesterol Treatment Trialists' (CTT) Collaborators. Efficacy and safety of cholesterol-lowering treatment: prospective meta-analysis of data from 90,056 participants in 14 randomised trials of statins. Lancet. 2005;366:1267-78. http://dx.doi.org/10.1016/S01406736(05)67394-1

56. Ray KK, Seshasai SR, Erqou S, Sever P, Jukema JW, Ford I, et al. Statins and allcause mortality in high-risk primary prevention: a meta-analysis of 11 randomized controlled trials involving 65,229 participants. Arch Intern Med. 2010;170:1024-31.

http://dx.doi.org/10.1001/archinternmed. 2010.182

57. Taylor F, Ward K, Moore TH, Burke M, Davey Smith G, Casas JP, et al. Statins for the primary prevention of cardiovascular disease. Cochrane Database Syst Rev. 2011;1:CD004816.

58. Abramson JD, Rosenberg HG, Jewell N, Wright JM. Should people at low risk of cardiovascular disease take a statin? BMJ. 2013;347:f6123.

59. de Lorgeril M, Salen P, Abramson J, Dodin S, Hamazaki T, Kostucki W, et al. Cholesterol lowering, cardiovascular disease, and the rosuvastatin-JUPITER controversy: a critical reappraisal. Arch Intern Med. 2010;170:1032-6.

http://dx.doi.org/10.1001/archinternmed. 2010.184

60. de Lorgeril $M$, Salen $P$, Defaye $P$, Rabaeus M. Recent findings on the health effects of omega-3 fatty acids and statins, and their interactions: do statins inhibit omega-3? BMC Med. 2013;11:5.

http://dx.doi.org/10.1186/1741-7015-11-5

61. de Lorgeril M. The JUPITER and statin controversy. American Heart Association, Los Angeles 2012. Available at:

http://michel.delorgeril.info/conferences/ diapositives-congres-de-1-aha-a-losangeles.
Accessed November 10, 2015.

62. Montori VM, Devereaux PJ, Adhikari NK, Burns $\mathrm{KE}$, Eggert $\mathrm{CH}$, Briel $\mathrm{M}$, et al. Randomized trials stopped early for benefit: a systematic review. JAMA. 2005;294:2203-9. http://dx.doi.org/10.1001/jama.294.17.2203

63. Bassler D, Briel M, Montori VM, Lane M, Glasziou P, Zhou Q, et al. Stopping randomized trials early for benefit and estimation of treatment effects: systematic review and meta-regression analysis. JAMA. 2010;303:1180-7.

http://dx.doi.org/10.1001/jama.2010.310

64. Ridker PM, Pradhan A, MacFadyen JG, Libby P, Glynn RJ. Cardiovascular benefits and diabetes risks of statin therapy in primary prevention: an analysis from the JUPITER trial. Lancet. 2012;380:565-71.

http://dx.doi.org/10.1016/S01406736(12)61190-8

65. Halimi S. Do not forget that type 2 diabetes does not only expose to cardiovascular complications. Diabetes Metab. 2014;40:167-8.

http://dx.doi.org/10.1016/j.diabet.2014.0 $\underline{3.005}$

66. Cowey S, Hardy RW. The metabolic syndrome: a high-risk state for cancer? Am J Pathol. 2006;169:1505-22.

http://dx.doi.org/10.2353/ajpath.2006.05 $\underline{1090}$

67. Sieri S, Muti P, Claudia A, Berrino F, Berrino F, Pala V, Grioni S, et al. Prospective study on the role of glucose metabolism in breast cancer occurrence. Int J Cancer. 2012;130:921-9.

http://dx.doi.org/10.1002/ijc.26071

68. Bordier L, Doucet J, Boudet J, Bauduceau B. Update on cognitive decline and dementia in elderly patients with diabetes. Diabetes Metab. 2014;40:331-7. http://dx.doi.org/10.1016/j.diabet.2014.0 $\underline{2.002}$

69. Carnevale V, Romagnoli E, D'Erasmo L, D'Erasmo E. Bone damage in type 2 diabetes mellitus. Nutr Metab Cardiovasc Dis. 2014;27:1151-7.

http://dx.doi.org/10.1016/j.numecd.2014. $\underline{06.013}$ 
70. Pan A, Lucas M, Sun Q, van Dam RM, Franco $\mathrm{OH}$, Manson JE, et al: Bidirectional association between depression and type 2 diabetes mellitus in women. Arch Intern Med. 2010;170:1884-91.

http://dx.doi.org/10.1001/archinternmed. $\underline{2010.356}$

71. Horwich TB, MacLellan WR, Fonarow GC. Statin therapy is associated with improved survival in ischemic and nonischemic heart failure. J Am Coll Cardiol. 2004;43:642-8

http://dx.doi.org/10.1016/j.jacc.2003.07. $\underline{049}$

72. Mozaffarian D, Nye R, Levy WC. Statin therapy is associated with lower mortality among patients with severe heart failure. Am J Cardiol. 2004;93:1124-9.

http://dx.doi.org/10.1016/j.amjcard.2004. $\underline{01.039}$

73. Go AS, Lee WY, Yang J, Lo JC, Gurwitz JH. Statin therapy and risks for death and hospitalization in chronic heart failure. JAMA. 2006;296:2105-11.

http://dx.doi.org/10.1001/jama.296.17.21 $\underline{05}$

74. Scandinavian Simvastatin Survival Study Group. Randomised trial of cholesterol lowering in 4444 patients with coronary heart disease: the Scandinavian Simvastatin Survival Study (4S). Lancet. 1994;344:1383-9.

75. Orn S, Cleland JG, Romo M, Kjekshus J, Dickstein K. Recurrent infarction causes the most deaths following myocardial infarction with left ventricular dysfunction. Am J Med. 2005; 118:752-8.

http://dx.doi.org/10.1016/j.amjmed.2005. $\underline{02.010}$

76. Strippoli GF, Navaneethan SD, Johnson DW, Perkovic V, Pellegrini F, Nicolucci A, et al. Effects of statins in patients with chronic kidney disease: meta-analysis and metaregression of randomised controlled trials. BMJ. 2008;336:645-51.

http://dx.doi.org/10.1136/bmj.39472.580 984.AE

77. Wanner C, Krane V, März W, Olschewski M, Mann JF, Ruf G, et al.; for the German Diabetes and Dialysis Study Investigators.
Atorvastatin in patients with type 2 diabetes mellitus undergoing hemodialysis. N Engl J Med. 2005;353:238-48.

http://dx.doi.org/10.1056/NEJMoa043545

78. Hou W, Lv J, Perkovic V, Yang L, Zhao $\mathrm{N}$, Jardine $\mathrm{MJ}$, et al. Effect of statin therapy on cardiovascular and renal outcomes in patients with chronic kidney disease: a systematic review and metaanalysis. Eur Heart J. 2013;34:1807-17. http://dx.doi.org/10.1093/eurheartj/eht0 $\underline{65}$

79. Palmer SC, Craig JC, Navaneethan SD, Tonelli M, Pellegrini F, Strippoli GF. Benefits and harms of statin therapy for persons with chronic kidney disease: a systematic review and meta-analysis. Ann Intern Med. 2012;157:263-75.

http:/ /dx.doi.org/10.7326/0003-4819$\underline{157-4-201208210-00007}$

80. Baigent C, Landray MJ, Reith C, Emberson J, Wheeler DC, Tomson C, et al.; SHARP Investigators. The effects of lowering LDL cholesterol with simvastatin plus ezetimibe in patients with chronic kidney disease (Study of Heart and Renal Protection): a randomised placebocontrolled trial. Lancet. 2011;377:2181-92. http://dx.doi.org/10.1016/S0140$\underline{6736(11) 60739-3}$

81. Trial-Results Center. SHARP trial, description and results. Available at: http://www.trialresultscenter.org/study80 81-SHARP.htm.

Accessed November 15, 2015.

82. Nicholls SJ, Ballantyne CM, Barter PJ, Chapman MJ, Erbel RM, Libby $\mathrm{P}$, et al. Effect of two intensive statin regimens on progression of coronary disease. $\mathrm{N}$ Engl J Med. 2011;365:2078-87.

http://dx.doi.org/10.1056/NEJMoa11108 $\underline{74}$

83. Schwartz GG1, Olsson AG, Ezekowitz MD, Ganz P, Oliver MF, Waters D, et al.; for the Myocardial Ischemia Reduction with Aggressive Cholesterol Lowering (MIRACL) Study Investigators: Effects of atorvastatin on early recurrent ischemic events in acute coronary syndromes: the MIRACL study: a randomized controlled trial. JAMA. 2001;285:1711-8. 
84. Waters D, Schwartz GG, Olsson AG. The Myocardial Ischemia Reduction with Acute Cholesterol Lowering (MIRACL) trial: a new frontier for statins? Curr Control Trials Cardiovasc Med. 2001;2:111-4.

85. National Clinical Guideline Centre (UK). Lipid Modification: Cardiovascular Risk Assessment and the Modification of Blood Lipids for the Primary and Secondary Prevention of Cardiovascular Disease. London: National Institute for Health and Care Excellence (UK), 2014.

86. Briel M, Schwartz GG, Thompson PL, de Lemos JA, Blazing MA, van Es GA, et al. Effects of early treatment with statins on short-term clinical outcomes in acute coronary syndromes: a meta-analysis of randomized controlled trials. JAMA. 2006;295:2046-56.

http://dx.doi.org/10.1001/jama.295.17.20 46

87. Vale N, Nordmann AJ, Schwartz GG, de Lemos J, Colivicchi F, den Hartog F, et al. Statins for acute coronary syndrome. Cochrane Database Syst Rev. 2014;9:CD006870.

88. Heart Protection Study Collaborative Group. MRC/BHF Heart Protection Study of cholesterol lowering with simvastatin in 20,536 high-risk individuals: a randomised placebo-controlled trial. Lancet. 2002;360: 7-22.

89. Pedersen TR, Faergeman O, Kastelein JJ, Olsson AG, Tikkanen MJ, Holme I, et al.; for the Incremental Decrease in End Points Through Aggressive Lipid Lowering (IDEAL) Study Group: High-dose atorvastatin vs usual-dose simvastatin for secondary prevention after myocardial infarction: the IDEAL study: a randomized controlled trial. JAMA. 2005;294:2437-45. http://dx.doi.org/10.1001/jama.294.19.24 $\underline{37}$

90. Cholesterol Treatment Trialists' (CTT) Collaboration, Baigent C, Blackwell L, Emberson J, Holland LE, Reith C, Bhala N, et al. Efficacy and safety of more intensive lowering of LDL cholesterol: a metaanalysis of data from 170,000 participants in 26 randomized trials. Lancet. 2010;376:1670-81.
91. Study of the Effectiveness of Additional Reductions in Cholesterol and Homocysteine (SEARCH) Collaborative Group, Armitage J, Bowman L, Wallendszus K, Bulbulia R, Rahimi K, Haynes $\mathrm{R}$, et al. Intensive lowering of $\mathrm{LDL}$ cholesterol with $80 \mathrm{mg}$ versus $20 \mathrm{mg}$ simvastatin daily in 12,064 survivors of myocardial infarction: a double-blind randomised trial. Lancet. 2010;376:165869 Erratum in: Lancet. 2011;377:126.

92. Cannon CP, Braunwald E, McCabe $\mathrm{CH}$, Rader DJ, Rouleau JL, Belder R, et al.; for the Pravastatin or Atorvastatin Evaluation and Infection Therapy-Thrombolysis in Myocardial Infarction 22 Investigators: intensive versus moderate lipid lowering with statins after acute coronary syndromes. N Engl J Med. 2004;350:1495504. Erratum in: $\mathrm{N}$ Engl $\mathrm{J}$ Med. 2006;354:778.

93. Cannon CP, Braunwald E, McCabe $\mathrm{CH}$, Grayston JT, Muhlestein B, Giugliano RP, et al.; for the Pravastatin or Atorvastatin Evaluation and Infection TherapyThrombolysis in Myocardial Infarction 22 Investigators. Antibiotic treatment of Chlamydia pneumoniae after acute coronary syndrome. N Engl J Med. 2005;352:1646-54.

http://dx.doi.org/10.1056/NEJMoa043528

94. Neumann A, Maura G, Weill A, Ricordeau P, Alla F, Allemand $\mathrm{H}$. Comparative effectiveness of rosuvastatin versus simvastatin in primary prevention among new users: a cohort study in the French national health insurance database. Pharmacoepidemiol Drug Saf. 2014;23:240-245.

http://dx.doi.org/10.1002/pds.3544

95. Glynn RJ, Danielson E, Fonseca FA, Genest J, Gotto AM Jr, Kastelein JJ, et al. A randomized trial of rosuvastatin in the prevention of venous thromboembolism. N Engl J Med. 2009;360:1851-61. http://dx.doi.org/10.1056/NEJMoa09002 $\underline{41}$

96. Rahimi K, Bhala N, Kamphuisen P, Emberson J, Biere-Rafi S, Krane V, et al: Effect of statins on venous thromboembolic events: a meta-analysis of published and unpublished evidence from randomised 
controlled trials. PLoS Med. 2012;9:e1001310.

http://dx.doi.org/10.1371/journal.pmed.1 001310

97. FDA announces safety changes in labeling for some cholesterol-lowering drugs. Available at:

http: / / www.fda.gov/NewsEvents/Newsr oom/PressAnnouncements/ucm293623. htm.

Accessed October 10, 2015.

98. Saini P, Loke YK, Gamble C, Altman DG, Williamson PR, Kirkham JJ. Selective reporting bias of harm outcomes within studies: findings from a cohort of systematic reviews. BMJ. 2014;349:g6501.

99. Bero LA. Why the Cochrane risk of bias tool should include funding source as a standard item. Cochrane Database of System Rev. 2013;12:ED000075.

100. Muscogiuri G, Sarno G, Gastaldelli A, Savastano S, Ascione A, Colao A, et al. The good and bad effects of statins on insulin sensitivity and secretion. Endocr Res. 2014;39:137-43.

http://dx.doi.org/10.3109/07435800.201 4.952018

101. Jukema JW, Cannon CP, de Craen AJ, Westendorp RG, Trompet S. The controversies of statin therapy: weighing the evidence. J Am Coll Cardiol. 2012;60:875-81.

http://dx.doi.org/10.1016/j.jacc.2012.07. $\underline{007}$

102. Sattar N, Preiss D, Murray HM, Welsh P, Buckley BM, de Craen AJ, et al. Statins and risk of incident diabetes: a collaborative meta-analysis of randomised statin trials. Lancet. 2010;375:735-42. http://dx.doi.org/10.1016/S01406736(09)61965-6

103. Ridker PM, Pradhan A, MacFadyen JG, Libby P, Glynn RJ. Cardiovascular benefits and diabetes risks of statin therapy in primary prevention: an analysis from the JUPITER trial. Lancet. 2012;380:565-71.

http://dx.doi.org/10.1016/S01406736(12)61190-8
104. de Lorgeril M, Hamazaki T, Kostucki W, Okuyama H, Pavy B, McGill AT, et al. Is the use of cholesterol-lowering drugs for the prevention of cardiovascular complications in type 2 diabetics evidencebased? A systematic review. Rev Recent Clin Trials. 2012;7:150-7.

105. Chang YH, Hsieh MC, Wang CY, Lin $\mathrm{KC}$, Lee YJ. Reassessing the benefits of statins in the prevention of cardiovascular disease in diabetic patients - a systematic review and meta-analysis. Rev Diabet Stud. 2013;10:157-70.

http://dx.doi.org/10.1900/RDS.2013.10.157

106. Hung SH, Lin HC, Chung SD. Statin use and thyroid cancer: a population-based case-control study. Clin Endocrinol (Oxf). 2015;83:111-116.

http://dx.doi.org/10.1111/cen. 12570

107. Vinogradova Y, Coupland C, HippisleyCox J. Exposure to statins and risk of common cancers: a series of nested casecontrol studies. BMC Cancer. 2011;11:409. http:/ /dx.doi.org/ 10.1186/1471-2407-11409

108. de Lorgeril M, Salen P. Do statins increase and Mediterranean diet decrease the risk of breast cancer? BMC Med. 2014;12:94.

http://dx.doi.org/10.1186/1741-7015-12-94

109. Hoffman KB, Kraus C, Dimbil M, Golomb BA. A survey of the FDA's AERS database regarding muscle and tendon adverse events linked to the statin drug class. PLoS One. 2012;7:e42866.

http://dx.doi.org/10.1371/journal.pone.0 042866

110. Golomb BA, Evans MA, Dimsdale JE, White HL. Effects of statins on energy and fatigue with exertion: results from a randomized controlled trial. Arch Intern Med. 2012;172:1180-2.

http://dx.doi.org/10.1001/archinternmed. 2012.2171

111. Cham S, Evans MA, Denenberg JO, Golomb BA. Statin-associated muscle-related adverse effects: a case series of 354 patients. Pharmacotherapy. 2010;30:541-53. http://dx.doi.org/10.1592/phco.30.6.541 
112. Ravnskov U, McCully KS, Rosch PJ. The statin - low cholesterol - cancer conundrum. QJM. 2012;105:383-8. http://dx.doi.org/10.1093/qjmed/hcr243

113. You H, Lu W, Zhao S, Hu Z, Zhang J. The relationship between statins and depression: a review of the literature. Expert Opin Pharmacother. 2013;14: 1467-76.

http://dx.doi.org/10.1517/14656566.201 $\underline{3.803067}$

114. Gøtzsche PC. Muscular adverse effects are common with statins. BMJ. 2014;348:g3724.

115. Redberg RF, Katz MH. Reassessing benefits and risks of statins. N Engl J Med. 2012;367:776.

http://dx.doi.org/10.1056/NEJMc120707 9\#SA1

116. Abramson JD, Rosenberg HG, Jewell $\mathrm{N}$, Wright JM. Should people at low risk of cardiovascular disease take a statin? BMJ. 2013;347:f6123.

117. Sun GH: Statins: The Good, the Bad, and the Unknown. Available at:

http://www.medscape.com/viewarticle/8 32841?src=wnl_int_edit_tp10\&uac $=78143$ HG.

Accessed December 1, 2015.

118. Culver AL, Ockene IS Balasubramanian R, Olendzki BC, Sepavich DM, Wactawski-Wende J, et al. Statin use and risk of diabetes mellitus in postmenopausal women in the Women's Health Initiative. Arch Intern Med. 2012;172:144-52.

http://dx.doi.org/10.1001/archinternmed. $\underline{2011.625}$

119. Corrao G, Ibrahim B, Nicotra F, Soranna D, Merlino L, Catapano AL, et al: Statins and the risk of diabetes: evidence from a large population-based cohort study. Diabetes Care. 2014;37:2225-32. http: / / dx.doi.org/10.2337/dc13-2215

120. Zaharan NL, Williams D, Bennett K. Statins and risk of treated incident diabetes in a primary care population. $\mathrm{Br} \mathrm{J}$ Clin Pharmacol. 2013;75:1118-24. http://dx.doi.org/10.1111/j.1365-

$\underline{2125.2012 .04403 . x}$

121. Cederberg H, Stančáková A, Yaluri N Modi S, Kuusisto J, Laakso M. Increased risk of diabetes with statin treatment is associated with impaired insulin sensitivity and insulin secretion: a 6 year follow-up study of the METSIM cohort. Diabetologia. 2015;58:1109-1117.

122. Colhoun HM, Betteridge DJ, Durrington PN, Hitman GA, Neil HA, Livingstone SJ, et al.; for the CARDS Investigators. Primary prevention of cardiovascular disease with atorvastatin in type 2 diabetes in the Collaborative Atorvastatin Diabetes Study (CARDS): a multicentre randomised placebo-controlled trial. Lancet. 2004;364:685-96.

http://dx.doi.org/10.1016/S01406736(04)16895-5

123. Knopp RH, d'Emden M, Smilde JG, Pocock SJ. Efficacy and safety of atorvastatin in the prevention of cardiovascular end points in subjects with type 2 diabetes: the Atorvastatin Study for Prevention of Coronary Heart Disease Endpoints in non-insulin-dependent diabetes mellitus (ASPEN). Diabetes Care. 2006;29:1478-85.

http://dx.doi.org/ 10.2337/dc05-2415

124. Kearney PM, Blackwell L, Collins R, Keech A, Simes J, Peto R, et al., for the Cholesterol Treatment Trialists' (CTT) Collaborators. Efficacy of cholesterollowering therapy in 18,686 people with diabetes in 14 randomised trials of statins: a meta-analysis. Lancet. 2008;371:117125 .

125. März W, Genser B, Drechsler C, Krane V, Grammer TB, Ritz E, et al.; German Diabetes and Dialysis Study Investigators: Atorvastatin and low-density lipoprotein cholesterol in type 2 diabetes mellitus patients on hemodialysis. Clin J Am Soc Nephrol. 2011;6:1316-25.

http://dx.doi.org/10.2215/CJN.09121010

126. American Diabetes Association. Standards of medical care in diabetes 2011. Diabetes Care. 2011;34 (Suppl 1):S1 1-61. 
127. American Heart Association. Cardiovascular disease and diabetes: Available:

http://www.heart.org/HEARTORG/ Conditions/Diabetes/WhyDiabetes Matters/Cardiovascular-DiseaseDiabetes_UCM_313865_Article. jsp.

Accessed November 12, 2015.
128. Gøtzsche PC. Big pharma often commits corporate crime, and this must be stopped. BMJ. 2012;345:e8462.

129. Ioannidis JP. More than a billion people taking statins? Potential implications of the new cardiovascular guidelines. JAMA. 2014;311:463-4.

http://dx.doi.org/10.1001/jama.2013.284657 